\title{
O Exame Nacional do Ensino Médio (Enem) e as competências para uma Educação Estatística Crítica
}

Justiani Hollas a

Lucí T. M. dos Santos Bernardi ${ }^{b}$

\section{Resumo}

O artigo coloca em tela o Exame Nacional do Ensino Médio (Enem), importante exame de avaliação de larga escala no Brasil, e tem por objetivo discutir como as questões de estatística propostas nas provas do Enem podem contribuir para o desenvolvimento de uma Educação Estatística Crítica no ensino médio brasileiro. A pesquisa é de cunho teórico: bibliográfica e documental. Na primeira etapa, caracterizamos as competências de uma Educação Estatística Crítica: raciocínio estatístico, pensamento estatístico e literacia estatística. Na segunda, mapeamos as provas do período de 1998 até 2018, analisando todas as questões de estatística, da área de Matemática e suas Tecnologias. $\mathrm{O}$ estudo nos permite inferir que: i) é possível desenvolver uma Educação Estatística Crítica no ensino médio, e indicamos alguns elementos potencializadores para os processos educativos; ii) o Enem, nos parâmetros em que está organizado, não pode ser seu elemento mobilizador, pois carece de elementos críticos, reflexivos, problematizações e contextualizações, impulsionando uma formação acrítica.

Palavras-chave: Educação Estatística Crítica. Enem. Ensino Médio. Competências.

\section{Introdução}

O delineamento de nossas questões no presente trabalho perpassa por olhar o processo de avaliação em larga escala, que nas últimas décadas adquiriu grande importância no cenário educacional brasileiro. Referimo-nos às inúmeras ações que foram desenvolvidas pelos governos, através do Sistema Nacional de Avaliação da Educação Básica (SAEB), a Prova Brasil e o Exame Nacional do Ensino Médio (Enem), cujos dados são utilizados para mapear locais de necessidade de

\footnotetext{
a Universidade Comunitária da Região de Chapecó, Chapecó, SC, Brasil.

b Universidade Regional Integrada do Alto Uruguai e das Missões, Frederico Westphalen, RS, Brasil. 
maior atenção, subsidiando o cálculo do Índice de Desenvolvimento da Educação Básica (IDEB) e a elaboração de políticas educacionais.

Na esteira do importante papel que cada ação desempenha, colocamos em tela, de forma específica, o Enem, que se tornou um exame histórico para a educação brasileira. Além de avaliar os estudantes que concluem o ensino médio, tal exame instala-se como uma ferramenta para o estabelecimento de índices de qualidade da educação básica e contribui com a efetivação, ou não, de políticas educacionais. Em outro aspecto também pode ser considerado um processo seletivo para o ingresso na Educação Superior, e, por isso, influencia a mobilização por mudanças nos processos educativos do ensino médio no intuito de preparar os estudantes para a prova.

Sampaio (2010) afirma que o exame influencia a prática em sala de aula, ao propor objetivos de ensino de Matemática e induzir a metodologia de trabalho; Malusá, Ordones e Ribeiro (2014) corroboram apontando o Enem como um instrumento para a reforma do ensino médio, que exerce influência na qualidade da educação brasileira. Barros (2014) vai além, ao compreender que o estudante é treinado para a realização dessa prova a partir do $6^{\circ}$ ano do Ensino Fundamental, passando quase uma década da sua vida estudando conteúdos que servem apenas como bagagem para o Enem e para o vestibular, muitas vezes não possuindo conexão com o seu cotidiano.

O elemento balizador do presente estudo foram as provas do Enem, no período de 1998 (sua criação) até 2018, tendo, como foco, as questões de estatística, na área de Matemática e suas Tecnologias.

Inserido na disciplina de matemática, no ensino fundamental e médio, o conteúdo de estatística pode envolver muitos dados numéricos e informações, mas, ao mesmo tempo que contempla resultados absolutos, pode propiciar uma leitura do mundo e uma visão mais ampla de situações aparentemente verdadeiras. Segundo Seife (2015), pessoas que dominam o conhecimento de técnicas estatísticas podem aparentar verdades em circunstâncias falsas. Os números "podem ser usados para oprimir os inimigos, destruir os críticos e pôr fim a discussão" (2015, p. 13). Neste sentido, podem existir situações em que os dados estatísticos são manipulados para responder determinadas questões.

A estatística trabalhada na perspectiva crítica objetiva superar circunstâncias opressoras e de mera transmissão de conhecimentos. Consideramos importante a formação para a dúvida e a incerteza, ou seja, o questionamento acerca do que chega aos olhos e ouvidos dos estudantes, caracterizando uma educação mais 
crítica e preparada, frente ao grande número de informações disponíveis na realidade atual, que possa ter relação com o cotidiano dos estudantes.

Nessa perspectiva, encontramos na Educação Estatística pressupostos que podem ser potencializados por intermédio da Educação Crítica ${ }^{1}$, no anseio do desenvolvimento de uma Educação Estatística Crítica.

Nesse cenário, impulsionadas por leituras exploratórias sobre a temática, desenvolvemos a presente pesquisa com o objetivo de compreender como as questões de estatística do Enem - edições de 1998 a 2016 - podem contribuir para o desenvolvimento de uma Educação Estatística Crítica no ensino médio brasileiro.

Consideramos que o Enem é uma política de avaliação que exerce importante papel regulador no ensino médio, e levantamos possibilidades de que é viável desenvolver uma Educação Estatística Crítica no ensino médio, e que pode ter, no Enem, seu elemento mobilizador.

O texto está assim organizado: num primeiro momento descrevemos as competências de uma Educação Estatística Crítica, apresentamos os fios teóricos em que ancoramos os seus pressupostos que são: raciocínio estatístico, pensamento estatístico e literacia estatística, pensando nesses elementos para a formação na perspectiva crítica. Posteriormente, apresentamos uma contextualização do Enem e descrevemos a análise das questões de estatística nas edições de 1998 a 2018. Por fim, são apontadas contribuições da Educação Crítica e da Educação Matemática Crítica para potencializar as competências da Educação Estatística Crítica com um olhar sobre o Enem e, também, na formação em geral. Nas Considerações Finais, retomamos os objetivos iniciais da pesquisa averiguando-as e fazendo uma retrospectiva do estudo, apontando as principais características e conclusões.

\section{Competências de uma Educação Estatística Crítica}

Ao se voltar para a resolução de problemas sociais, a estatística demonstra que pode ser um assunto que desenvolve o senso crítico. Podem ser desenvolvidas práticas, em que o estudante se torna o centro do ensino e do currículo. Portanto, valorizar as problemáticas do contexto do estudante pode resultar em um maior envolvimento e em reflexão-ação, promovendo uma ponte entre escola, conhecimento e comunidade.

\footnotetext{
Em uma educação crítica, o estudante faz parte da práxis pedagógica, sujeito da sua história e de participação no destino do país. Segundo Skovsmose, "Isso nos traz a educação crítica: a educação não pode apenas representar uma adaptação às prioridades políticas e econômicas (quaisquer que sejam); a educação deve engajar-se no processo político, incluindo uma preocupação com a democracia" (2007a, p. 19).
} 
Com base nos estudos de Campos, Wodewodzki e Jacobini (2011), defendemos que a Educação Estatística Crítica busca promover avanços em estudos correlacionados ao tema; auxiliar o trabalho do professor na sala de aula e dos pesquisadores, por intermédio de embasamento teórico; melhorar a metodologia de ensino do conteúdo centrada em competências a serem desenvolvidas, valorizando a formação de uma postura crítica, reflexiva e de tomada de decisões.

Os autores ressaltam também que, muitas vezes, a estatística é abordada na sala de aula, dando prioridade aos aspectos técnicos e operacionais. Nesse sentido, apontam, como uma alternativa de mudança, um ensino centrado na participação efetiva do estudante:

Assim, ele é levado a responsabilizar-se pelas informações, a compreender e a refletir sobre as atividades que estão sendo desenvolvidas e tirar conclusões com base nos resultados obtidos. A investigação, a descoberta, a reflexão e a validação se destacam, pois são vistas como elementos básicos nesse processo de construção do conhecimento (CAMPOS; WODEWODZKI; JACOBINI, 2011, p. 14).

Os estudantes são instigados a compreender o processo estatístico, desde a investigação estatística até a explanação de resultados com claros objetivos a serem alcançados. Campos, Wodewodzki e Jacobini (2011) descrevem os objetivos do processo de ensino da estatística que podem ser alcançados pelos estudantes: i) entender processos de amostragem e de coleta de dados; ii) estabelecer relações matemáticas através de cálculos (como moda, média, mediana, amplitude total, desvio-padrão, entre outros); iii) aplicar a probabilidade e a incerteza, desenvolver habilidades de interpretação, reflexão, análise crítica e argumentação; iv) utilizar corretamente a linguagem dos conceitos estatísticos; v) aprender a trabalhar em equipe, com e para a comunidade; vi) questionar dados e informações que aparecem em seu contexto; vii) transpor aprendizagens para o seu cotidiano, atuando como cidadão e profissional.

Além de concordar com os objetivos expostos, corroboramos com a seguinte complementação: viii) desenvolver a autoconfiança dos estudantes, mostrando que todos são capazes de desenvolver uma pesquisa estatística e também seus próprios dados; ix) estimular a criatividade para desenvolverem métodos singulares de pesquisa e exposição de resultados.

Para explicitar as competências que os estudantes podem desenvolver no contexto dos processos educativos da Estatística, nos ancoramo em Machado (2012), que 
defende a ideia de que competência é a capacidade de mobilizar aquilo que se sabe para um determinado âmbito ou contexto, para realizar aquilo que se deseja ou que se projeta. De acordo com o autor, só podemos ser competentes junto com os outros, e, não, na individualidade, logo uma pessoa competente precisa ser integrada com os outros.

A partir da tessitura empreendida com elementos da Educação Estatística e da Educação Crítica, construímos um quadro relacional das competências propostas e, na sequência, abordamos cada uma delas.

As competências possuem conexão e pode existir interseção entre duas ou três delas como é possível observar na Figura 1. Acreditamos que o desenvolvimento das competências pode ter como elemento mobilizador a perspectiva crítica, e tal mobilização é uma forma de superar a prática da memorização de conceitos e de fórmulas estatísticas.

\subsection{Raciocínio estatístico}

A palavra raciocínio tem várias definições, porém para a Educação Estatística (EE) ela possui um significado específico. De acordo com Hulsizer e Woolf (2009,

Figura 1 - Competências de uma Educação Estatística Crítica

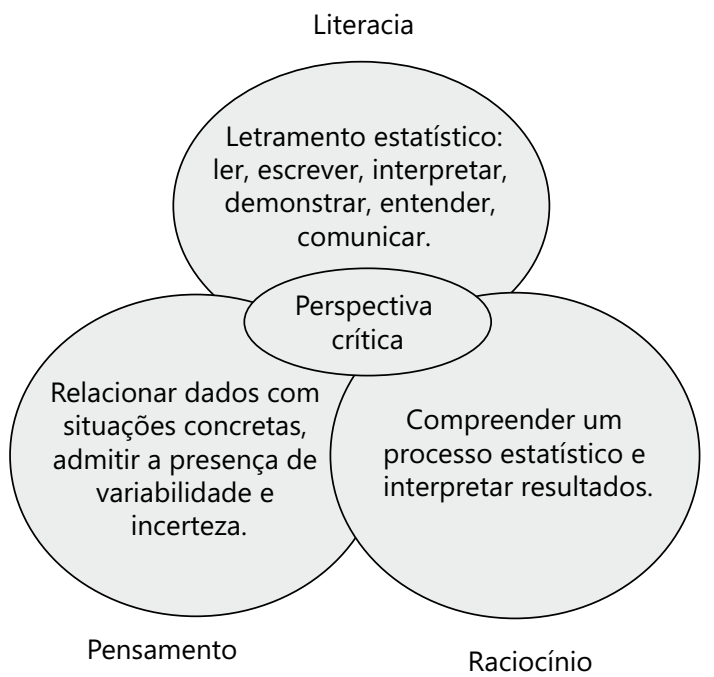

EEC

Fonte: Elaboração das autoras (2017) 
p. 67, tradução nossa), "[...] geralmente os termos raciocínio e pensamento são confundidos ou intercambiados nos discursos relacionados à EE, porém, cada termo possui características específicas”. Também existem diferenças entre raciocínio matemático e raciocínio estatístico.

Nessa competência, são importantes as habilidades de construção de gráficos e de tabelas, e a interpretação de dados. A estatística é uma ciência interpretativa. Conforme Hulsizer e Woolf (2009, p. 66, tradução nossa):

O raciocínio estatístico é o exame do processo subjacente de procedimentos estatísticos e pesquisas - o porquê, como explicação do processo. Não é o suficiente para que alguém seja capaz de calcular a probabilidade, mas eles devem ser capazes de aplicar esse raciocínio para a vida toda e em situações que envolvam raciocínio probabilístico para o mundo real.

O raciocínio estatístico se diferencia do raciocínio matemático ao considerarmos os dados estatísticos como números que expressam um contexto real, podendo envolver ideias de probabilidade, variabilidade, incerteza, amostra, testes de hipótese etc.

Os tipos de raciocínio estatístico referem-se a: dados, representação dos dados, medidas estatísticas, incertezas, amostras e associações. Ao estudante são oportunizados a compreensão de todas as fases da pesquisa, assim como estabelecer conexões entre elas.

\subsection{Pensamento estatístico}

Os avanços tecnológicos tornaram o trabalho do cálculo mais correto e ágil, mudando o enfoque dos pesquisadores que antes era o de encontrar resultados numéricos, para atividades de perceber o pensamento estatístico e os resultados encontrados. "Pensamento estatístico envolve o processo de aplicação, crítica, avaliação e generalização. Em geral, pensamento estatístico envolve a compreensão do panorama geral da conceituação de pesquisa para a conclusão" (HULSIZER; WOOLF, 2009, p. 63, tradução nossa).

Campos (2007, p. 54) destaca hábitos mentais e habilidades do pensamento estatístico que estão parafraseados a seguir: i) compreender qual o melhor método de obter dados significantes e relevantes para responder à questão que se tem em mãos; ii) reflexão constante sobre as variáveis envolvidas e curiosidade por maneiras diversificadas de examinar os dados e o problema em pesquisa; iii) visualizar 
o processo globalmente, com constante revisão de cada parte do processo; iv) ceticismo ubíquo sobre a obtenção dos dados; v) relacionamento constante entre os dados e o contexto do problema e interpretação das conclusões em termos não estatísticos; vi) pensar além do livro-texto e da abordagem de sala de aula.

Desse modo, referimo-nos, então, em ver o processo de maneira global, com suas variabilidades, perceber hipóteses e fazer outras previsões, usar a criatividade para encontrar maneiras diversificadas de se examinar um problema e suas soluções.

\subsection{Literacia estatística}

Segundo a origem, o termo literacia vem da palavra literacy, que se configura como a habilidade para ler e escrever. Conforme Hulsizer e Woolf (2009, p. 59, tradução nossa), literacia estatística representa a habilidade e os conhecimentos mínimos necessários para que as pessoas possam "viajar" objetivamente em informações diárias. Portanto, ela está voltada para a capacidade de cada indivíduo exercer sua cidadania, apropriando-se das informações do cotidiano e tomando decisões coerentes para transformar a realidade.

Isso significa que o estudante que desenvolver esta competência estará letrado estatisticamente, sendo capaz de compreender conceitos e utilizar o vocabulário e símbolos. Além disso, é a capacidade de extrair conclusões e pensar criticamente sobre as informações disponibilizadas diariamente para, assim, poder exercer sua cidadania estatística.

A literacia estatística

[...] refere-se ao estudo de argumentos que usam a estatística como referência, ou seja, à habilidade de argumentar usando corretamente a terminologia estatística. [...] Essas habilidades incluem as capacidades de organizar dados, construir e apresentar tabelas e trabalhar com diferentes representações dos dados (CAMPOS; WODEWODZKI; JACOBINI, 2011, p. 23).

Os professores têm a tarefa de tornar o ensino das fórmulas e técnicas mais significativas. Segundo Campos, Wodewodzki e Jacobini (2011, p. 25): "Promover o COMO em detrimento do PORQUÊ no ensino de Estatística é um erro". Concordando com essa afirmação, completamos com o exemplo: de nada adianta ensinar a fórmula da variância sem o estudante compreender os objetivos da 
pesquisa e para que público está voltada, ou, ainda, se esse mesmo público não consegue analisar o valor numérico encontrado e fazer comparações.

Outra análise que merece destaque é a capacidade de o professor envolver o estudante com o conteúdo, uma alternativa é estimular os estudantes a produzir seus próprios dados, estipulando suas variáveis de pesquisa e seus próprios processos de amostragem, sem deixar de lado a formalidade e a cientificidade da estatística.

Nesta esteira, podem ser resolvidos e pesquisados problemas do contexto escolar e da comunidade, ou, até mesmo, serem criadas situações em que se apliquem pesquisas estatísticas, como exemplo, pode ser utilizado à pesquisa de opinião. Ao final da pesquisa, o professor pode estimular a habilidade escrita, por meio de análises e conclusões. Por fim, pode promover ambientes de troca de experiências descontraídos e com a participação de todos.

É preciso que eles aprendam a usar a Estatística como evidencia nos argumentos encontrados na vida diária como trabalhadores, consumidores e cidadãos. Além disso, ensinar Estatística com base em assuntos do dia a dia tende não apenas a melhorar a base de argumentação dos estudantes, mas também aumentar o valor e a importância que eles dão a essa disciplina (CAMPOS; WODEWODZKI; JACOBINI, 2011, p. 28).

É possível concluir que, na literacia estatística, o estudante necessita de conhecimentos matemáticos, conhecimentos estatísticos, mas, também, de características individuais que se referem à atitude crítica, realização de questionamentos e generalização de alguns resultados. Em todas as etapas, é importante o estímulo pela autoconfiança do estudante em seu trabalho e do olhar crítico sobre os dados.

\section{As Questões do Enem: um olhar sobre as competências}

O Enem é um exame de avaliação imponente, de larga escala, pois atinge um grande número de pessoas e, todo ano, está presente nas discussões, elencado a temas como: educação, juventude, educação superior, indicadores oficiais do ensino médio, entre outros. Foi instituído pelo Instituto Nacional de Estudos e Pesquisas Educacionais Anísio Teixeira (Inep) ${ }^{2}$, ocorrendo sua primeira edição em 1998.

O Inep é uma autarquia federal vinculada ao Ministério da Educação (MEC), cuja missão é promover estudos, pesquisas e avaliações sobre o Sistema Educacional Brasileiro. Dentre os principais objetivos estão o subsídio da formulação e implementação de políticas públicas6 para a área educacional a partir de parâmetros de qualidade e equidade, bem como a produção de informações claras e confiáveis aos gestores, pesquisadores, educadores e público em geral. 
O seu objetivo inicial era avaliar a qualidade do ensino médio no Brasil. Ao longo do tempo, o exame passou por muitas reformulações e, aos poucos, o papel do Enem passou a ser uma das formas de ingressar na educação superior. Conforme Malusá, Ordones e Ribeiro (2013, p. 360), “[...] tal reestruturação teve como principal objetivo motivador a democratização de oportunidades de acesso ao ensino superior, o que também ajudou a estimular a reorganização do currículo do ensino médio".

Atualmente o Enem é utilizado por instituições de educação superior, públicas e privadas, como critério para seleção de candidatos e para concorrer a bolsas de estudos. Além disso, quem faz o exame pode inscrever-se em programas do governo federal como Programa Universidade Para Todos (ProUni), Ciências Sem Fronteiras, Fundo de Financiamento Estudantil (FIES), Programa Nacional de Acesso ao Ensino Técnico e Emprego (Pronatec) e ingressar em Instituições de Educação Superior portuguesas ${ }^{3}$.

O público do Enem são estudantes que estão concluindo ou egressos do Ensino Médio, que, desde 2010, passou a ser um exame de certificação para pessoas desse nível de ensino. Porém, a realização do exame não é obrigatória, por isso, não atende todos os que estão aptos a realizá-lo, e essa característica faz com que os resultados não possam ser estendidos ao conjunto universo.

O número de inscrições no Enem foi sempre crescente, com exceção dos anos de 2004, 2007 e 2015 em que ocorreu decrescimento, como é possível observar no Gráfico 1.

Conforme o documento básico do Enem (BRASIL, 2001), existem três eixos que são desafios da política educacional brasileira: a superação dos entraves macroestruturais; a intervenção para o aperfeiçoamento dos modelos de ensino e o preparo para a vida profissional; e o alargamento do gargalo imposto pelas condições do sistema de educação superior público e do mercado profissional de trabalho. Até 2008, o Enem era composto por 63 questões, organizadas em cinco competências e 21 habilidades. Em 2009, o exame passou a ter 180 questões, que continuam baseadas em habilidades ${ }^{4}$ e competências.

\footnotetext{
De acordo com informações da Capes, as concessões de bolsas do CsF foram finalizadas em 2014 e concluiu as atividades no início de 2017. Disponível em: http://www.capes.gov.br/pt/36-noticias/8052-programa-cienciasem-fronteiras-tera-novo-foco-com-objetivo-de-beneficiar-alunos-mais-pobres. Acesso em: 06 jun. 2019.

4 Competências são as modalidades estruturais da inteligência, ou melhor, ações e operações que utilizamos para estabelecer relações com e entre objetos, situações, fenômenos e pessoas que desejamos conhecer. As habilidades decorrem das competências adquiridas e referem-se ao plano imediato do "saber fazer". Por meio das ações e operações, as habilidades aperfeiçoam-se e articulam-se, possibilitando nova reorganização das competências (BRASIL, 2001, p. 7).
} 
Gráfico 1 - Número de inscritos no Enem de 1998 a 2018

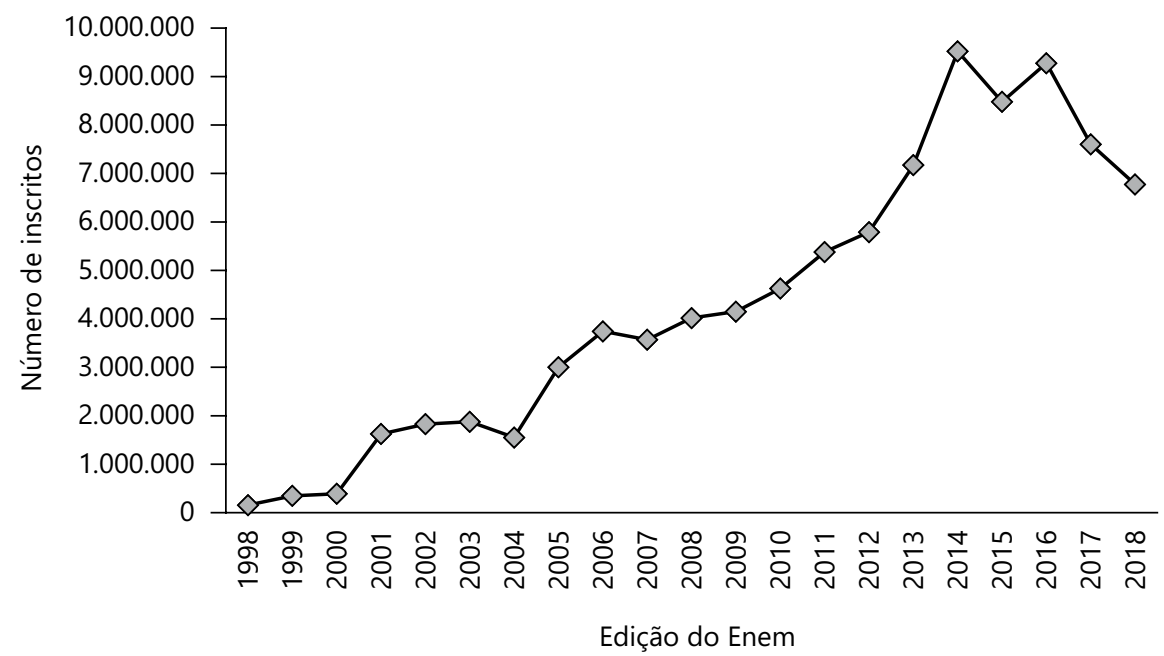

Fonte: Elaboração das autoras (2019), com dados do portal MEC/Inep

A mobilização de conhecimentos requerida pelo Enem manifestase por meio da estrutura de competências e habilidades do participante que o possibilita ler (perceber) o mundo que o cerca, simbolicamente representado pelas situações-problema; interpretá-lo (decodificando-o, atribuindo-lhe sentido) e sentindo-se 'provocado', agir, ainda que em pensamento (atribui valores, julga, escolhe, decide, entre outras operações mentais) (BRASIL, 2001, p. 15).

Portanto, segundo Pereira e Souza (2016, p. 326), em 2009 ocorreu uma reformulação das matrizes de referência, deste modo até o ano de 2016 o exame oferecia a oportunidade de certificação para o ensino médio. A partir de 2017, o Enem deixa de certificar o ensino médio, tarefa que volta a ser cumprida pelo Exame Nacional para Certificação de Competências de Jovens e Adultos (Encceja), próprio para essa finalidade.

Para se chegar aos resultados dessa pesquisa foi realizada uma triagem minuciosa em todas as provas realizadas e, em específico, todas as questões ${ }^{5}$ da área da Matemática e suas Tecnologias. Foram consideradas em todas as edições do Enem, desde o ano de 1998 até 2018, portanto, o conjunto universo da pesquisa

\footnotetext{
5 Para mais informações e download de provas e gabaritos de todas as edições do Enem, sugerimos como fonte de pesquisa o site: portal.inep.gov.br.
} 
correspondente a 2.160 questões, das quais foram identificadas e analisadas 166 questões com conteúdos de estatística.

A fim de dinamizar a análise, elaboramos o Quadro 1, de parâmetros referentes ao conteúdo de estatística sob a luz da Educação Estatística Crítica. Cada grupo é numerado, em ordem crescente, conforme a proximidade com as competências.

O Parâmetro 1 são questões que exigem leitura e interpretação do gráfico e/ou tabela e escolha da alternativa adequada, sem a presença de nenhum cálculo ou utilizando apenas alguns como as quatro operações básicas (adição, subtração, multiplicação e divisão) ou porcentagem.

O Parâmetro 2 é o grupo de questões que, além da interpretação, requerem a utilização de cálculos estatísticos, como a média, moda, mediana e desvio-padrão.

No Parâmetro 3 são analisadas questões que propiciam uma conexão com o contexto do estudante. O pensamento estatístico significa ver o processo de maneira global, perceber variabilidades, hipóteses, usar a criatividade para encontrar maneiras diversificadas de examinar um problema e suas soluções.

O Parâmetro 4 é composto por questões em que o estudante pode entender o processo estatístico e interpretar resultados, enfim, o estudante pode trabalhar com os dados da pesquisa, organizando-os.

O Parâmetro 5 é formado por questões que desenvolvem habilidades como organizar dados, construir e apresentar tabelas e trabalhar com diferentes representações dos dados. Ou seja, ler, escrever, interpretar e comunicar resultados.

Todas as questões foram estudadas e classificadas. A análise completa pode ser consultada em Hollas (2017, p. 80-83). A título de exemplo, selecionamos quatro questões do exame aplicado no ano de 2008, apresentadas na Figura 2.

Quadro 1 - Parâmetros atribuídos às questões de estatística nas provas do Enem, 1998-2018

\begin{tabular}{|l|c|c|c|c|c|}
\hline Parâmetro & Parâmetro 1 & Parâmetro 2 & Parâmetro 3 & Parâmetro 4 & Parâmetro 5 \\
\hline Descrição & $\begin{array}{c}\text { Leitura e } \\
\text { interpretação }\end{array}$ & $\begin{array}{c}\text { Habilidades } \\
\text { de cálculos } \\
\text { estatísticos }\end{array}$ & $\begin{array}{c}\text { Pensamento } \\
\text { estatístico }\end{array}$ & $\begin{array}{c}\text { Raciocínio } \\
\text { estatístico }\end{array}$ & $\begin{array}{c}\text { Literacia } \\
\text { estatística }\end{array}$ \\
\hline
\end{tabular}

Fonte: Elaborado pelas autoras (2017) 
Figura 2 - Questões do Enem, ano 2008

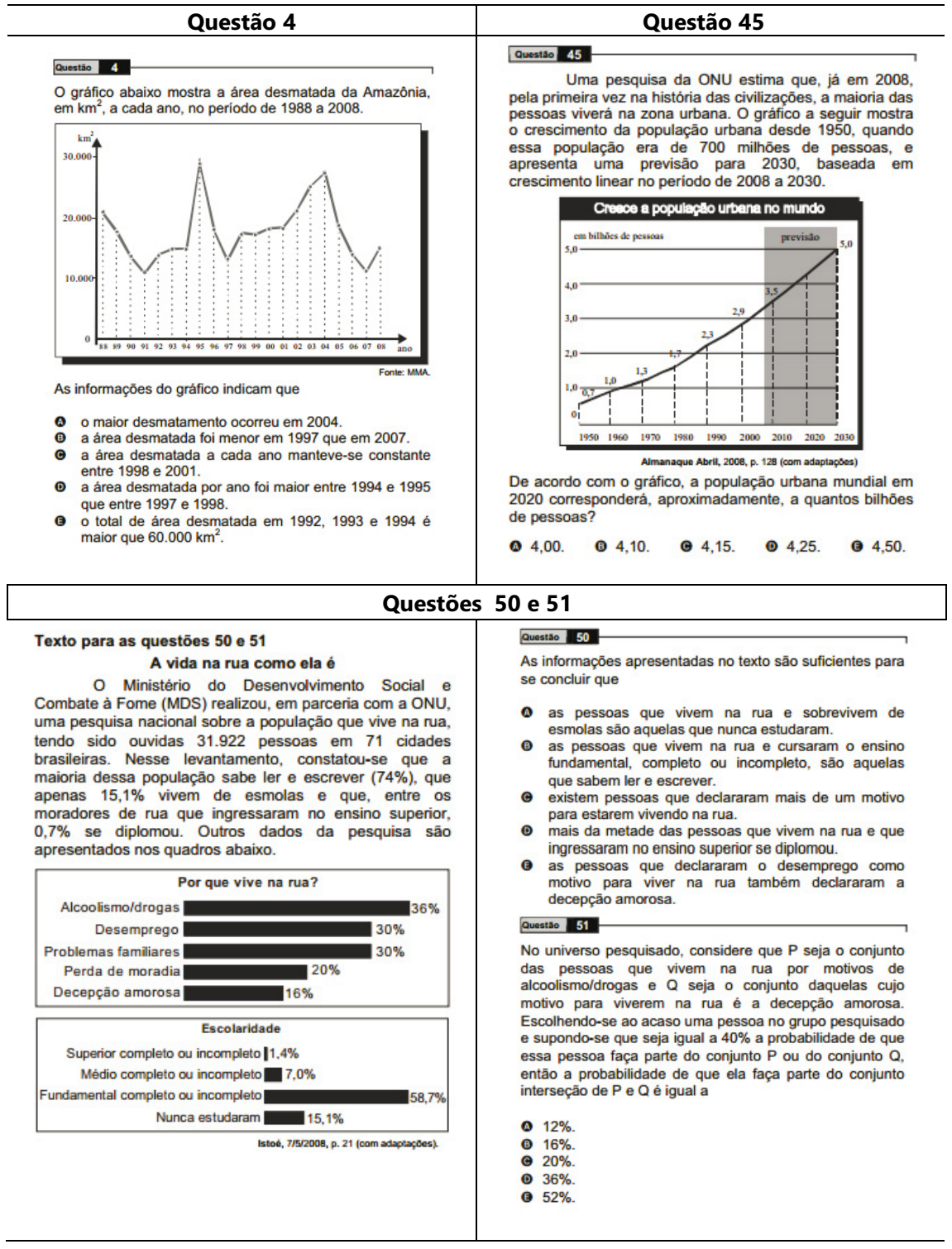

Fonte: Elaborada pelas autoras (2017)

Portanto, ao analisar o tema, o conteúdo e a relação pergunta e resposta das questões, é possível fazer a classificação indicada no Quadro 2. 
Quadro 2 - Classificação de questões Enem, ano 2008

\begin{tabular}{|c|c|c|c|c|c|}
\hline Parâmetro & Parâmetro 1 & Parâmetro 2 & Parâmetro 3 & Parâmetro 4 & Parâmetro 5 \\
\hline $\begin{array}{l}\text { Relações } \\
\text { entre os } \\
\text { parâmetros }\end{array}$ & - & $\begin{array}{c}1 \text { está } \\
\text { contido em } 2\end{array}$ & $\begin{array}{l}1 \text { e } 2 \text { estão } \\
\text { contidos } \\
\text { em } 3\end{array}$ & $\begin{array}{c}\text { 1, } 2 \text { e } 3 \text { estão } \\
\text { contidos } \\
\text { em } 4\end{array}$ & $\begin{array}{l}1,2,3 \text { e } \\
4 \text { estão } \\
\text { contidos } \\
\text { em } 5\end{array}$ \\
\hline $\begin{array}{l}N^{\circ} \text { da } \\
\text { questão }\end{array}$ & 4 e 45 & 51 & 50 & - & - \\
\hline $\begin{array}{l}\text { Habilidades } \\
\text { necessárias } \\
\text { na resolução }\end{array}$ & $\begin{array}{l}\text { Exemplo } \\
\text { de questões } \\
\text { classificadas no } \\
\text { parâmetro 1: } \\
\text { Questão } \\
\text { 4, possível } \\
\text { responder } \\
\text { as perguntas } \\
\text { através da } \\
\text { análise do } \\
\text { gráfico ou } \\
\text { tabela e escolha } \\
\text { da alternativa } \\
\text { correta. Na } \\
\text { questão } 45 \\
\text { pode ser } \\
\text { realizado um } \\
\text { cálculo de } \\
\text { proporção, } \\
\text { composto por } \\
\text { operações } \\
\text { básicas da } \\
\text { matemática. }\end{array}$ & $\begin{array}{l}\text { Na questão } \\
51 \text { é exigido o } \\
\text { conhecimento } \\
\text { de cálculo de } \\
\text { probabilidades. } \\
\text { Por isso, são } \\
\text { classificadas } \\
\text { como } \\
\text { parâmetro } 2 \text {. }\end{array}$ & $\begin{array}{l}\text { Na questão } 50 \\
\text { o estudante } \\
\text { pode pensar } \\
\text { nos problemas } \\
\text { sociais da } \\
\text { cidade onde } \\
\text { vive, pois os } \\
\text { moradores de } \\
\text { rua podem ser } \\
\text { encontrados } \\
\text { em muitos } \\
\text { contextos } \\
\text { brasileiros. }\end{array}$ & - & - \\
\hline
\end{tabular}

Fonte: Elaborado pelas autoras (2017)

As relações entre os parâmetros significam que existe conexão entre eles. Por exemplo, o parâmetro 2 contém habilidades do parâmetro 1 e o parâmetro 5 contém habilidades e competências de todos. Portanto, não são formados por competências e habilidades específicas, mas apresentam as mesmas características do anterior com um nível de aprofundamento maior nas competências da Educação Estatística Crítica.

Extrapolando essa mesma análise para o universo de 166 questões de estatística, foi construída a Tabela 1, que apresenta o número de questões conforme o parâmetro mais adequado. 
Tabela 1 - Classificação das questões de conteúdo estatístico do Enem de 1998 a 2018 conforme parâmetros

\begin{tabular}{|c|c|c|c|c|c|c|}
\hline $\begin{array}{l}\text { Classificação/ } \\
\text { Edição }\end{array}$ & $\begin{array}{c}\text { Parâmetro } \\
1\end{array}$ & $\begin{array}{c}\text { Parâmetro } \\
2\end{array}$ & $\begin{array}{c}\text { Parâmetro } \\
\mathbf{3}\end{array}$ & $\begin{array}{c}\text { Parâmetro } \\
4\end{array}$ & $\begin{array}{c}\text { Parâmetro } \\
5\end{array}$ & $\begin{array}{c}\text { Total de } \\
\text { questões } \\
\text { analisadas }\end{array}$ \\
\hline 1998 & 4 & 2 & - & - & - & 6 \\
\hline 1999 & 3 & 1 & - & - & - & 4 \\
\hline 2000 & 1 & - & - & - & - & 1 \\
\hline 2001 & 5 & 4 & 3 & - & - & 12 \\
\hline 2002 & 3 & 1 & - & - & - & 4 \\
\hline 2003 & 5 & 2 & - & - & - & 7 \\
\hline 2004 & 10 & 1 & 3 & - & - & 14 \\
\hline 2005 & 8 & 1 & 1 & - & - & 10 \\
\hline 2006 & 3 & 3 & 2 & - & - & 8 \\
\hline 2007 & 4 & 3 & - & - & - & 7 \\
\hline 2008 & 8 & 2 & 2 & - & - & 12 \\
\hline 2009 & 3 & 8 & - & - & - & 11 \\
\hline 2010 & 2 & 7 & - & - & - & 9 \\
\hline 2011 & 1 & 5 & - & - & - & 6 \\
\hline 2012 & 4 & 2 & 1 & - & - & 7 \\
\hline 2013 & 6 & 3 & - & - & - & 9 \\
\hline 2014 & 3 & 5 & 1 & - & - & 9 \\
\hline 2015 & 2 & 3 & - & - & - & 5 \\
\hline 2016 & 2 & 6 & - & - & - & 8 \\
\hline 2017 & 8 & 1 & - & - & - & 9 \\
\hline 2018 & 5 & 3 & - & - & - & 8 \\
\hline Total & 90 & 63 & 13 & 0 & 0 & 166 \\
\hline$\%$ & 54,22 & 37,95 & 7,83 & 0 & 0 & 100 \\
\hline
\end{tabular}

Fonte: Elaborada pela autoras (2019)

Através do estudo, identificamos que a contextualização das questões ocorre por meio de representações em gráficos e tabelas, para que os candidatos possam fazer a interpretação dos dados e em algumas vezes, realizar cálculos matemáticos básicos (utilizando conteúdos como porcentagem, razão, proporção, quatro operações) e cálculos estatísticos como média, moda, mediana e desvio-padrão. 
Consideramos que o parâmetro 1 e 2 são compostos pelas questões mais tecnicistas ${ }^{6}$, às quais, para as respostas são aplicadas apenas fórmulas e conceitos matemáticos. A partir do parâmetro 3, o estudante pode desenvolver sua perspectiva crítica, ao entrar em contato com questões que relacionam a sua vida e a sociedade em geral, fazendo críticas em relação a algumas situações.

Também podemos concluir que o Enem aborda, de forma parcial, as habilidades referentes à Matriz de Referência de Matemática e suas Tecnologias, na competência de Área 6, que se refere a: "Interpretar informações de natureza científica e social obtidas da leitura de gráficos e tabelas, realizando previsão de tendência, extrapolação, interpolação e interpretação".

Essa competência descreve um conjunto de habilidades que os estudantes deveriam construir na resolução das questões de estatística. Dentre elas, citamos aquelas que os estudantes não encontram nas questões de estatística do Enem: i) ser capaz de fazer inferências; ii) analisar informações expressas em gráficos ou tabelas como recurso para a construção de argumentos; iii) construir argumentações; iv) avaliar propostas de intervenção na realidade, utilizando conhecimentos de estatística e probabilidade.

\section{Possibilidades de uma Educação Estatística Crítica}

Retomamos os parâmetros utilizados na análise das questões do Enem e enfatizamos que existem conexões entre todos os parâmetros. O parâmetro 1 está contido no parâmetro 2, que, por sua vez, está contido no parâmetro 3 , e, assim, sucessivamente, portanto, utilizamos o conceito de competência como um conjunto de habilidades (Figura 3).

Para desenvolver a Literacia Estatística (parâmetro 5) é importante ter desenvolvido o raciocínio e o pensamento estatístico que são formados por um conjunto de habilidades, e, não, por habilidades isoladas. Nossa tese é de que as questões do Enem podem priorizar a Literacia, ou seja, não se reduzir nos parâmetros 1, 2 e 3 , mas avançar para 4 e 5 .

Nessa mesma direção, concordamos com Depresbiteris (2002) que os instrumentos e técnicas de avaliação deveriam possibilitar observação de como as pessoas pensam para resolver um problema, como um processo mediador, dialógico, interativo e dinâmico. Porém, o que avistamos no Enem são características de um

Aquelas em que são utilizadas fórmulas e conceitos técnicos da matemática memorizados durante a vida escolar, podem ser consideradas questões neutras, que não se preocupam com maiores reflexões críticas. 
Figura 3 - Sequência dos parâmetros analisados nas questões do Enem Competências da EEC

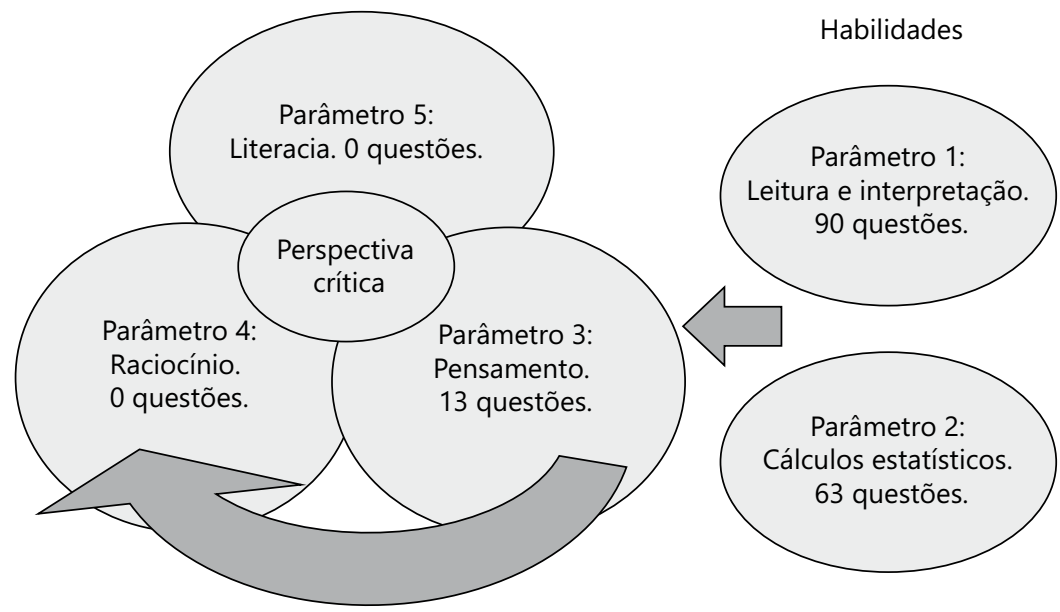

EEC

Fonte: Elaborada pelas autoras (2017)

exame tradicional, elaborado para avaliar o estoque de informações do candidato através de questões objetivas e precisas.

Ainda, no âmbito pedagógico das provas, podemos concordar com Depresbiteris (2002, p. 38) "que essas provas não medem as concepções dos alunos, suas estratégias de aprendizagem, seus processos de pensamento relacionados com o ensino".

Nesse sentido, na região de inquérito da Estatística, o Enem não contribui como uma avaliação formadora de consciência crítica dos cidadãos candidatos da prova, pois a maneira como estão elaboradas as questões deixam em aberto a relação com situações do cotidiano e impossibilita o desenvolvimento de argumentações críticas. Também voltamos a pontuar a formação em competências com o que Machado (2012) caracteriza como a mobilização do conteúdo estudado para a argumentação, decisão e à capacidade de extrapolar os conteúdos e contextos, o que não observamos no exame.

Portanto, sobre o papel regulador e influenciador do Enem, no ensino médio, concluímos que pode impulsionar uma formação acrítica, especialmente pela carência de elementos críticos, reflexivos, problematizações e contextualizações 
com o cotidiano dos estudantes. Porém, evidenciamos nele a possibilidade de desenvolver e impulsionar uma Educação Estatística Crítica, influenciando também na formação dos estudantes.

\section{Potencializando a Educação Estatística Crítica: os processos educativos}

Em uma análise geral, podemos concluir que as questões não atingiram as competências analisadas, que são o Pensamento Estatístico, Raciocínio Estatístico e Literacia Estatística. Algumas questões exigiam apenas algumas habilidades presentes nessas competências e também há fortes indícios que o Enem aborda de forma parcial a formação estatística, não apresentando um conjunto de competências necessárias para o desenvolvimento de uma Educação Estatística Crítica.

Questionamo-nos, então, como as competências da Educação Estatística Crítica podem ser potencializadas no cotidiano das escolas. Nesse âmbito, pensamos sobre a necessidade de outras preocupações emergirem, com inspiração na Educação Matemática Crítica, que se tem voltado a estudos sobre a educação, a matemática e a sociedade. Segundo Skovsmose (2010), a educação não muda profundamente uma sociedade, não estabelece novas estruturas sociopolíticas, mas pode trazer contribuições sobre justiça social, igualdade e autonomia. Temos a concepção de que a estatística trabalhada de maneira crítica também pode contribuir com essas características na educação.

Os dados estatísticos são vistos como números que podem representar um contexto, uma realidade. Como já defendemos ao longo do texto, a compreensão e reflexão acerca desses dados pode mudar a dinâmica de vida das pessoas, no sentido de se posicionar diante desse contexto e de tomarem decisões.

Apontamos a Educação Estatística Crítica como uma oportunidade de resistência, que perpassa a concepção capitalista de aprender apenas a ler, escrever e fazer cálculos básicos, que, em muitos casos, vem servindo como um espaço de preparação para o trabalho explorado, alienado, sem incitar futuras ações libertadoras. Os valores são transmitidos em caixinhas isoladas, em um sistema seriado, o qual reproduz a hierarquia dentro da escola.

Para Alro e Skovsmose (2010, p. 19), assim como Freire utilizava a Literacia como uma competência que vai além de apenas saber ler e escrever, na Educação Matemática Crítica, a matemacia tem um papel que corresponde à noção de 
literacia. "Isso nos traz a educação crítica: a educação não pode apenas representar uma adaptação às prioridades políticas e econômicas (quaisquer que sejam); a educação deve engajar-se no processo político, incluindo uma preocupação com a democracia" (SKOVSMOSE, 2007, p. 19).

Apontamos a importância da matemacia, parafraseando Skovsmose (2007), quando anuncia que é possível perceber que, assim como Paulo Freire pensou no letramento como algo maior que o ato de leitura e escrita como uma competência do cidadão crítico, a noção de contagem também pode ser compreendida como algo que vai além de operar com números, trazendo competências como ler e interpretar informações, números e figuras. Em Skovsmose (2015, p. 105) a matemacia foi definida "como uma competência para lidar com técnicas matemáticas", além de se tratada como um modo de ler o mundo, utilizando números e gráficos, tal como a literacia estatística.

Alro e Skovsmose $(2010$, p. 55) nominam de paradigma do exercício um ambiente de aprendizagem onde geralmente os exercícios são preparados por autores alheios a realidade da escola, apresentando na verdade, semirrealidades, de resolução do tipo "siga o modelo". Segundo os autores "a semirrealidade está completamente descrita no texto da questão. [...] O único propósito do exercício é ser resolvido".

Nesse contexto, podemos concluir que a literacia estatística desenvolve competências semelhantes às da matemacia, buscando superar o paradigma do exercício, pois, esse tipo de abordagem evita questionamentos considerados "desnecessários", formando obstáculo para a formação de ambientes de reflexão crítica sobre a realidade.

Por isso, é importante a problematização das questões da vida real dos estudantes na formulação de exercícios, pois, assim, é colocado em debate o absolutismo burocrático e o paradigma do exercício. Conforme Alro e Skovsmose (2010), é possível pensar em ambientes de aprendizagem que compõem cenários para investigação, em que as perspectivas dos estudantes são consideradas no processo chamado modelo de cooperação investigativa.

Concordamos com Alro e Skovsmose (2010, p. 123) que "realizar uma investigação significa abandonar as comodidades da certeza e deixar-se levar pela curiosidade". Em outras palavras eles apontam que "começar uma investigação significa assumir a condução da atividade" (2010, p. 124). Ou seja, os estudantes tornam-se agentes de construção do seu conhecimento, desenvolvendo autonomia. 
Em referência aos parâmetros utilizados para análise das questões do Enem, consideramos que 1 e 2 estão localizadas no contexto do paradigma de exercícios, apontados como uma sequência de comandos, uma receita ou manual pronto para ser seguido. Dinâmica que os estudantes estão habituados a enfrentar na educação básica, com inúmeros exercícios na lógica de seguir modelos prontos que aceitam apenas uma resposta como correta.

Skovsmose (2008) aponta sobre a importância da superação do paradigma do exercício em direção ao cenário para investigação e o movimento da matemática pura para a matemática que faz referência à realidade, contribuindo com a formação de um olhar mais crítico, principalmente, através da Educação Estatística Crítica.

No ambiente escolar, pensamos na Educação Estatística Crítica como formadora de competências de um sujeito crítico e reflexivo, quando o professor ultrapassa o paradigma de exercícios para os ambientes em que ocorrem investigações estatísticas e problematizações de situações reais.

Em geral, os exercícios estão preparados para refutar questionamentos considerados inúteis, isso é perceptível em questões de todos os tipos de conteúdos, essa característica determina apenas uma resposta como correta. Conforme Skovsmose (2015, p. 16), "ao longo de todo o período que frequentam a escola, as crianças, em sua maioria, respondem a mais de 10 mil exercícios". Consideramos que essa prática não contribui, necessariamente, com o aumento da aprendizagem nem com o desenvolvimento de competências estatísticas.

Além disso, existem exercícios que abordam apenas "a matemática pela matemática", ou seja, o uso de cálculos e aplicação direta de fórmulas. De forma específica, na estatística isso se concretiza em exercícios que exigem somente leitura e interpretação do gráfico e/ou tabela e escolha da alternativa adequada, sem nenhum ou utilizando apenas alguns cálculos básicos ou porcentagem, ou requer apenas a utilização de cálculos estatísticos, como a média, moda, mediana e desvio-padrão. É “a estatística pela estatística”.

Outro elemento que acreditamos contribuir com o processo educativo é o método de Paulo Freire, caracterizado por uma prática pedagógica para a conscientização. Concordamos com Simões (1981) que a conscientização visa à inserção crítica dos homens, em comunhão, na ação e na transformação. Nesse sentido, a nosso ver, os objetivos para a formação crítica do estudante na estatística são: i) estudar temas geradores que partem da sua própria realidade (pesquisa geradora: pesquisar e analisar seu próprio contexto), pois o estudante crítico é aquele que além de 
outros conhecimentos conhece a própria realidade; ii) promover a dialogicidade, oportunizando ao sujeito que faça parte da ação pedagógica que se promove no amor e na fé, mostrando que cada estudante é capaz de desenvolver pesquisas, organizar informações e tomar decisões a partir delas; iii) alcançar a conscientização para superar os desafios para a humanização e a libertação, extrapolando os dados e estabelecendo relações. iv) formar para a "leitura de mundo", "[...] a compreensão crítica da realidade, envolve, de um lado, sua denúncia, de outro, o anúncio do que ainda não existe." (2000, p. 42). Ou seja, educar como um ato político e transformador das realidades de vida e dos lugares de vivências.

Assim, nossa reflexão sobre os processos educativos nos mobilizou a pensar um quadro relacional ampliado de competências, em uma dinâmica que considera elementos que foram colocados em tela nesse trabalho, como potencializadores da Educação Estatística Crítica, como mostra a Figura 4.

A partir da Figura 4 compreendemos que tanto a matemacia, quanto a literacia estatística podem ser componentes propulsores para a Educação Estatística

Figura 4 - Potencializando a Educação Estatística Crítica

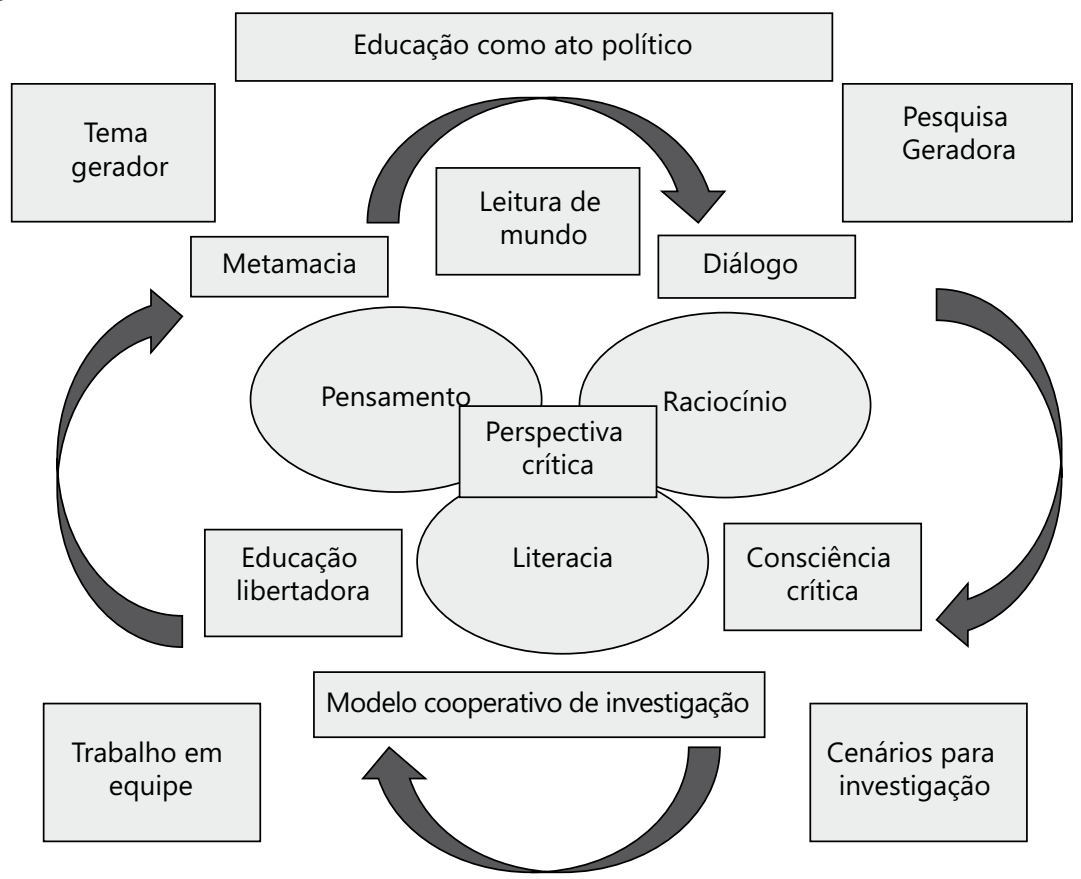

Fonte: Elaborada pelas autoras (2017) 
Crítica, pois têm como base uma formação para o pleno exercício da cidadania. Avaliamos que sua essência pode fomentar o desenvolvimento das três competências estatísticas.

A educação pode ser considerada um dos mais importantes meios de busca por transformações, pois a escola é o local de convívio social e de acolhimento da diversidade, por isso, também é um local de esperança e de resistência, local esse que, acima de tudo, acredita no ser humano.

\section{Considerações Finais}

Queremos ressaltar que nosso estudo mostrou a importância do Enem para o cenário educativo brasileiro, tanto no processo avaliativo, ao estabelecer índices de qualidades para a educação e promover o processo seletivo para o ingresso na educação superior, como elemento que tem a condição para mobilizar essa qualidade, tendo em vista a influência que exerce sobre os processos utilizados na educação básica.

Analisamos o conteúdo e a organização de cada questão apresentada nas provas do Enem no período de 1998-2018, na área de Matemática e suas Tecnologias. Com foco nas questões de estatística, concluímos que são de interpretação de gráficos e/ou tabelas, exigindo a utilização de poucos ou nenhum cálculo estatístico, deixando a desejar quanto ao raciocínio, pensamento e letramento estatístico. Concluímos também que a prova organizada de maneira objetiva pode oferecer alguns obstáculos para o desenvolvimento de questões que contemplem uma Educação Estatística Crítica, pois limitam as alternativas na formulação das questões.

A pesquisa bibliográfica contribuiu para a afirmação de que é possível desenvolver uma Educação Estatística Crítica, porém, na pesquisa documental - o Enem, nos parâmetros em que está organizado, não pode ser seu elemento mobilizador. Carece de elementos críticos, reflexivos, problematizações e contextualizações com o cotidiano dos estudantes, o que influencia, de forma direta, no ensino médio, podendo impulsionar uma formação acrítica. Reafirmamos aqui a importância da prova como balizadora dos processos educativos no ensino médio, envolvendo os estudantes, professores e gestores, na busca de um bom resultado no exame.

Em contraponto, o Enem tem a possibilidade de promover uma Educação Estatística Crítica, se tomar para si essa proposta em seus exames, para além 
da estatística, assumir para si o compromisso com uma Educação Crítica, que promova o empoderamento de nossos estudantes. Pensando no Enem e no processo educativo, apresentamos uma possibilidade de prática educativa que utilize e problematize situações da realidade, trazendo para o ambiente escolar e para o ensino da estatística, elementos como a matemacia, tema gerador, educação libertadora, diálogo, leitura de mundo e cenários para investigação. 


\title{
The National Examination of Middle School (Enem) and the competences for a Critical Statistical Education
}

\begin{abstract}
The article presents the National Upper Secondary Education Examination (Enem), an important examination of large scale evaluation in Brazil, and aims to discuss how the statistical issues proposed in the Enem tests can contribute to the development of a Critical Statistical Education in the Brazilian secondary education. The research is theoretical in nature: bibliographical and documentary. In the first stage, we characterized the competences of a Critical Statistical Education: statistical reasoning, statistical thinking and statistical literacy. In the second, we mapped the evidence from the period 1998 to 2016, analyzing all statistical issues in the area of Mathematics and its Technologies. The study allows us to infer that: i) it is possible to develop a Critical Statistical Education in upper secondary education, and we indicate some potential elements for educational processes; ii) Enem, in the parameters in which it is organized, cannot be its mobilizing element, because it lacks critical elements, reflective, problematizations and contextualizations, impelling an uncritical formation.
\end{abstract}

Keywords: Education Critical Statistics. Enem. Upper Secondary Education. Skills.

\section{El Examen Nacional de la Escuela Secundaria (Enem) y las competencias para una Educación Estadística Crítica}

\section{Resumen}

El artículo presenta el Examen Nacional de Escuela Secundaria (Enem), un importante examen de evaluación a gran escala en Brasil, y tiene como objetivo discutir cómo las preguntas estadísticas propuestas en las pruebas Enem pueden contribuir al desarrollo de una Educación Estadística Crítica. en la escuela secundaria brasileña. La investigación es de carácter teórico: bibliográfico y documental. En la primera etapa, caracterizamos las competencias de una Educación Estadística Crítica: razonamiento estadístico, pensamiento estadístico y alfabetización estadística. En la segunda, mapeamos la evidencia del periodo 1998 a 2018, analizando todos los problemas estadísticos en el área de Matemáticas y sus Tecnologías. El estudio nos permite inferir que: i) es posible desarrollar una Educación Estadística Crítica en la escuela secundaria, e indicamos algunos elementos potenciales para los procesos educativos; ii) Enem, en los parámetros en los que está organizado, no puede ser su elemento movilizador, ya que carece de elementos críticos, reflexivos, problematizaciones y contextualizaciones, impulsando una formación no crítica.

Palabras clave: Educación Estadística Crítica. Enem. Escuela Secundaria. Habilidades. 


\section{Referências}

ALRO, H.; SKOVSMOSE, O. Diálogo e aprendizagem em educação matemática. Belo Horizonte: Autêntica, 2010.

BARROS, A. S. X. Vestibular e Enem: um debate contemporâneo. Revista Ensaio: Avaliação e Políticas Públicas em Educação, Rio de Janeiro, v. 22, n. 85, p. 1057-1090, out./dez. 2014. https://doi.org/10.1590/S0104-40362014000400009

BRASIL. Ministério da Educação. Exame nacional do ensino médio: documento básico. Brasília, DF: INEP, 2001. Disponível em: http://portal. inep.gov.br/documents/186968/484421/ENEM+-+Exame+Nacional+do+Ensi no $+\mathrm{M} \% \mathrm{C} 3 \% \mathrm{~A} 9$ dio + documento $+\mathrm{b} \% \mathrm{C} 3 \% \mathrm{~A} 1$ sico+2002/193b6522-cd52-4ed2a30f-24c582ae941d?version=1.2. Acesso em: 10 fev. 2017.

CAMPOS, C. A educação estatística: uma investigação acerca dos aspectos relevantes à didática da estatística em cursos de graduação. 2007. Tese (Doutorado em Educação Matemática) - Instituto de Geociências e Ciências Exatas, Universidade Estadual Paulista, Rio Claro, 2007.

CAMPOS, C.; WODEWODZKI, M. L.; JACOBINI, O. Educação estatística: teoria e prática em ambientes de modelagem matemática. Belo Horizonte: Autêntica, 2011.

DEPRESBITERIS, L. Avaliação da aprendizagem: uma nova prática implica uma nova visão do ensino. In: RAPHAEL, H. S.; CARRARA, K. (orgs.). Avaliação sob exame. Campinas: Autores Associados, 2002. p. 23-51.

HOLLAS, J. Educação estatística crítica: uma investigação acerca do exame nacional do ensino médio. 2017. Dissertação (Mestrado em Educação) Unochapecó, Chapecó, SC, 2017.

HULSIZER, M.; WOOLF, L. A guide to teaching statics: inovations and best practises. Singapore: Utopia, 2009.

MACHADO, N. J. Educação por competências. Produção: Edições SM Educação, 2012. Online, 20min42s. Disponível em: http://www. nilsonjosemachado.net/aulas-e-ementas/. Acesso em: 6 jun. 2016.

MALUSÁ, S; ORDONES, L. L.; RIBEIRO, E. ENEM: pontos positivos para a educação brasileira. Revista Educação e Políticas em Debate, Uberlândia, v. 3, n. 2, p. 358-382, ago./dez. 2014. 
PEREIRA, F. A.; SOUZA, F. S. O Exame Nacional do Ensino Médio e a construção do letramento e pensamento estatístico. Educação Matemática Pesquisa, São Paulo, v. 18, n. 3, p. 1319-1343, 2016.

SAMPAIO, L. O. Educação estatística crítica: uma possibilidade? 2010. Tese (Doutorado em Educação Matemática) - Instituto de Geociências e Ciências Exatas, Universidade Estadual Paulista, Rio Claro, 2010.

SEIFE, C. Os números (não) mentem: como a matemática pode ser usada para enganar você. Rio de Janeiro: Zahar, 2015.

SIMÕES, J. J. (org.). Educação crítica e seu método. São Paulo: Loyola, 1981. (Coleção Paulo Freire).

SKOVSMOSE, O. Educação crítica: incerteza, matemática, responsabilidade. São Paulo: Cortez, 2007.

SKOVSMOSE, O. Convite para educação matemática crítica: educação matemática, cultura e diversidade. In: ENCONTRO NACIONAL DE EDUCAÇÃO MATEMÁTICA, 10., 2010, Salvador. Anais [...]. Salvador: Sociedade Brasileira de Educação Matemática, 2010. p. 1-16.

SKOVSMOSE, O. Desafios da reflexão em educação matemática crítica. Campinas: Papirus, 2008.

SKOVSMOSE, O. Um convite à educação matemática crítica. Campinas: Papirus, 2015.

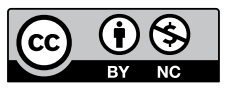

\section{Informações das autoras}

Justiani Hollas: Mestre em Educação pela Universidade Comunitária da Região de Chapecó. Professora da Rede Pública Estadual de Ensino de Santa Catarina. Contato: justiani@unochapeco.edu.br.

iD http://orcid.org/0000-0002-2747-6258

Lucí Teresinha Marchiori dos Santos Bernardi: Doutora em Educação Científica e Tecnológica pela Universidade Federal de Santa Catarina. Docente e Pesquisadora Permanente do Programa de Pós-Graduação em Educação da Universidade Regional Integrada do Alto Uruguai e das Missões. Contato: lucisantosbernardi@gmail.com

iD http://orcid.org/0000-0001-6744-9142 